\title{
Design and Manual to Construct Rainout-Shelters for Climate Change Experiments in Agroecosystems
}

\author{
Dominika Kundel ${ }^{1,2 * t}$, Svenja Meyer ${ }^{3+}$, Herbert Birkhofer ${ }^{4}$, Andreas Fliessbach ${ }^{1}$, \\ Paul Mäder ${ }^{1}$, Stefan Scheu ${ }^{3}$, Mark van Kleunen ${ }^{2,5}$ and Klaus Birkhofer ${ }^{6}$ \\ ${ }^{1}$ Soil Sciences Department, Research Institute of Organic Agriculture (FiBL), Frick, Switzerland, ${ }^{2}$ Department of Biology, \\ University of Konstanz, Konstanz, Germany, ${ }^{3}$ Animal Ecology, J.F. Blumenbach Institute for Zoology and Anthropology, \\ University of Göttingen, Göttingen, Germany, ${ }^{4}$ Product Development and Machine Elements, Faculty of Mechanical and \\ Process Engineering, Darmstadt University of Technology, Darmstadt, Germany, ${ }^{5}$ Zhejiang Provincial Key Laboratory of Plant \\ Evolutionary Ecology and Conservation, Taizhou University, Taizhou, China, ${ }^{6}$ Department of Ecology, Brandenburg University \\ of Technology, Cottbus, Germany
}

Climate change models predict reduced summer precipitations for most European countries, including more frequent and extreme summer droughts. Rainout-shelters which intercept part of the natural precipitation provide an effective tool to investigate effects of different precipitation levels on biodiversity and ecosystem functioning. In this study, we evaluate and describe in detail a fixed-location rainout-shelter $(2.5 \times 2.5 \mathrm{~m})$ with partial interception of natural rainfall. We provide a complete parts list, a construction manual and detailed CAD drawings allowing to rebuild and use these shelters for rainfall manipulation studies. In addition, we describe a rainout-shelter control treatment giving the possibility to quantify and account for potential shelter artifacts. To test the rainout-shelters, we established the following three treatments each in eight winter wheat plots of the agricultural long-term farming system comparison trial DOK in Therwil (Switzerland): (1) A rainout-shelter with 65\% interception of rainfall, (2) a rainout-shelter control without interception of rainfall, and (3) an ambient control. The rainout-shelter effectively excluded $64.9 \%$ of the ambient rainfall, which is very close to the a priori calculated exclusion of $65.1 \%$. In comparison to the ambient control plots, gravimetric soil moisture decreased under the rainout-shelter by a maximum of 11.1 percentage points. Air temperature under the rainout-shelter differed little from the ambient control $\left(-0.55^{\circ} \mathrm{C}\right.$ in $1.2 \mathrm{~m}$ height and $+0.19^{\circ} \mathrm{C}$ in $0.1 \mathrm{~m}$ height), whereas soil temperatures were slightly higher in periods of high ambient temperature $\left(+1.02^{\circ} \mathrm{C}\right)$, but remained basically unaffected in periods of low ambient temperature $\left(+0.14^{\circ} \mathrm{C}\right)$. A maximum edge effect of $0.75 \mathrm{~m}$ defined a sampling area of $1 \times 1 \mathrm{~m}$ under the rainout-shelter. The rainout-shelters presented here, proved to sustain under heavy weather and they were well-suited to be used in agricultural fields where management operations require the removal of the rainout-shelters for management operations. Overall, the results confirmed the good performance of the presented rainout-shelters regarding rainout-shelter artifacts, predictable rain exclusion, and feasibility for experimental studies in agricultural fields.

Keywords: rainout-shelter design, summer drought, climate change, precipitation, wheat, CAD drawings 


\section{INTRODUCTION}

Climate change models predict a future increase in temperature and altered precipitation regimes for Central Europe (Russo et al., 2013; Spinoni et al., 2015; EEA, 2017) as well as on a global scale (IPCC, 2014). For Switzerland, average annual precipitation is predicted to decrease by $21-28 \%$ by the end of the century, accompanied by more frequent drought events in summer $(\mathrm{CH} 2011,2011)$. Temperature and water availability are key drivers of ecosystem functioning and effects of these changing conditions are expected on biotic and abiotic system components (Porporato et al., 2004). Effects of altered precipitation are primarily documented from forest and grassland ecosystems (Blankinship et al., 2011), with far fewer studies from agroecosystems (Wu et al., 2011; Beier et al., 2012). Models for agricultural systems predict an increased risk of crop yield loss due to higher seasonal variation in precipitation and more frequent water shortages during the growing season (Olesen and Bindi, 2002; Falloon and Betts, 2010; Trnka et al., 2011; EEA, 2017). In order to understand how climate change affects biotic and abiotic components in agroecosystems, it is crucial to simulate such precipitation regimes under field conditions.

Field studies that experimentally alter rainfall primarily use rainout-shelters to exclude ambient precipitation from a predefined experimental area. One group of shelter types provides a complete or almost complete exclusion of precipitation by permanently closed roofs (Svejcar et al., 1999; Fay et al., 2000; Poll et al., 2013; Prechsl et al., 2015) or by roofs that are closing automatically during rain events (Mikkelsen et al., 2008; Parra et al., 2012). Roofs that only close during rain events minimize unintended shelter effects on the microclimate, as they are only closed for short periods of time (closed for $<5 \%$ of daytime, Mikkelsen et al., 2008). Yet, these roofs do not operate during strong wind, which often coincides with rainfall events and therefore do not exclude $100 \%$ of precipitation. The need for a motor and an electricity source for each roof makes this rainout-shelter type very costly for experimental designs with replicated sites and time consuming in terms of maintenance. Fixed rainout-shelters with permanently closed roofs, on the other hand, are often suitable for long-term studies. However, a complete exclusion of precipitation by a permanent roof inevitably has effects on the microclimate, such as alterations of air temperature and photosynthetic active radiation (PAR) (Beier et al., 2012). Further, in long-term studies, complete roofs necessarily need extra irrigation systems, otherwise they do not reflect realistic conditions under climate change as predicted for the next 50-100 years in most regions of Europe.

Major problems of permanent roofs relevant for biota and ecosystem processes include in particular passive warming (Svejcar et al., 1999; Fay et al., 2000; Vogel et al., 2013) and reduced PAR (Svejcar et al., 1999; Vogel et al., 2013). Reduced air circulation under complete exclusion roofs may lower the vapor-pressure deficit (VPD) and thereby reduce evapotranspiration, which in turn lowers the water demand of plants. The combination of complete exclusion roofs with irrigation systems that recirculate the intercepted rain water back onto the plots allows for flexible control of the amount of excluded precipitation (Svejcar et al., 1999; Fay et al., 2003; Castro et al., 2010), but holds the risk of changes in water chemistry (Beier et al., 2012). Again, such systems cannot be installed without access to electricity. Side-effects due to reduced air circulation and changes in water chemistry are limited by using roofs that only partially exclude rain (Yahdjian and Sala, 2002; Gimbel et al., 2015; Canarini et al., 2016). These roofs can further be designed to exclude pre-defined amounts of precipitation (e.g., according to predicted climate scenarios) during longterm experiments (Yahdjian and Sala, 2002). These authors used V-shaped acrylic bands (Figure 1C), which function as gullies to lead the water away and can have varying spacing in between to exclude pre-defined amounts of rain while minimizing effects on other environmental variables.

Here, we propose a revised design of the rainout-shelters by Yahdjian and Sala (2002) for the use in arable crop fields. We inspected potential side-effects of our design and provide a parts list, a construction manual and detailed CAD drawings (computer aided design) to allow construction of such rainout-shelters. The type of acrylic glass used for our rainout-shelters is highly UV-transparent, which is a major improvement over previously used shelter designs. We tested the effect of these rainout-shelters on basic abiotic conditions in cereal fields in an agricultural long-term experiment in Switzerland (DOK Trial, Mäder et al., 2002). To disentangle intended effects of the manipulated precipitation regime from unintended artifacts of the rainout-shelters, we further established two sets of control plots. Besides undisturbed plots that received ambient precipitation, we installed a replicated set of rainout-shelters that were identical to our original rainoutshelters, but allowed all natural precipitation to reach the area under the rainout-shelter (V-bands were turned over to become $\Lambda$-bands). The partial reduction of rainfall simulated by our rainout-shelters reflects predictions of future precipitation changes during the crop growing season in Central Europe (Russo et al., 2013; Spinoni et al., 2015; EEA, 2017). Our rainoutshelters are suitable for studies in a wide range of ecosystems, including agricultural systems, as they are both stable enough to endure extreme weather events in open land and are removable to allow for management activities. It is further possible to adapt the amount of excluded rainfall according to the needs of a study by adjusting the distance between the V-bands. In this manuscript, we provide a detailed description and evaluation of the proposed rainout-shelter design and discuss the performance of rainout-shelters considering intended and unintended effects on microclimate, soil moisture and edge effects.

\section{MATERIALS AND METHODS \\ Site Description and Design of Drought Manipulation Experiment}

We established rainout-shelters in the "DOK" farming system trial (bioDynamic, bioOrganic, Konventionell, Mäder et al., 2002). The DOK trial has been established in 1978 by the Swiss Federal Research Station for Agroecology and Agriculture 
A

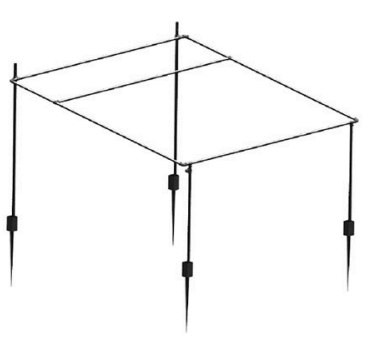

D

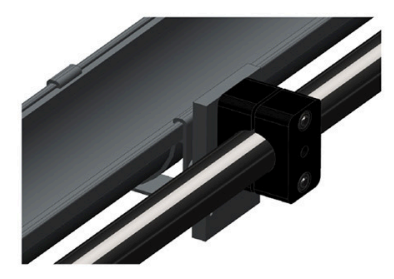

B

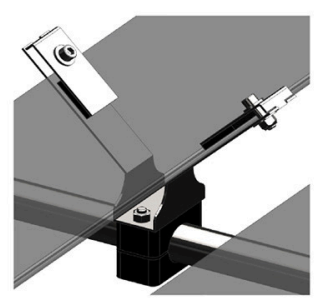

E

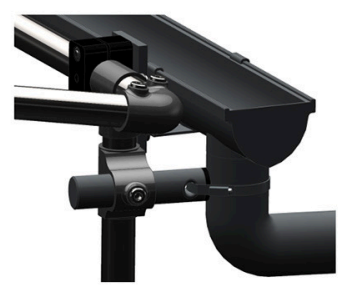

C

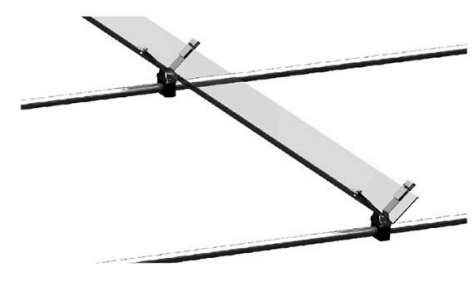

F

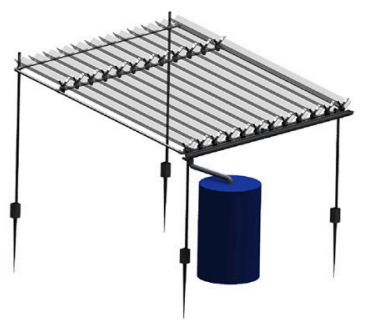

FIGURE 1 | (A) A metal frame $(2.5 \times 2.5 \mathrm{~m})$ serves as the basic rainout-shelter construction, the shelter is anchored in the soil using drive-in sleeves; (B) acrylic glass bands are fixed to the steel frame by specially designed holders; (C) the metal frame supports $\mathrm{V}$-shaped clear acrylic glass bands in which rainfall is collected; (D) rain gutter holder consist of pipe clamp, adapter plate, and gutter bracket (view from the rear); (E) a T-pipe connector with adaptor piece holds the drain pipe in place; (F) the final rainout-shelter with partial rainfall interception and precipitation collection.

(Zürich-Reckenholz, Switzerland) and the Research Institute of Organic Agriculture (Frick, Switzerland) to compare the production levels of arable crops under different organic and conventional farming systems (Fliessbach et al., 2007). The trial site is located in the Leimen valley near Basel, Switzerland $\left(47^{\circ} 30^{\prime} 09.3^{\prime \prime} \mathrm{N} 7^{\circ} 32^{\prime} 21.5^{\prime \prime} \mathrm{E}, 300\right.$ a.s.l. $)$ and has a slope of $3-$ $5 \%$ in $\mathrm{S}-\mathrm{N}$-direction. Mean annual temperature at the site is $9.5^{\circ} \mathrm{C}$ and mean annual precipitation is $785 \mathrm{~mm}$. The soil ( $15 \%$ clay, $70 \%$ silt, $15 \%$ sand, Fliessbach et al., 2007) at the site is a haplic luvisol on deposits of alluvial loess (Mäder et al., 2002). Soils in plots where the roofs were installed contained on average $11.9 \mathrm{mg}$ organic carbon per gram of soil.

The rainout-shelter design we present here was developed in the ERA-Net Biodiversa project "SOILCLIM" (http://www. biodiversa.org/976). The main aim of SOILCLIM is to investigate links between soil biodiversity and ecosystem functioning along natural and simulated precipitation gradients and different soil organic matter (SOM) levels.

We established three treatments in four replicated winter wheat (Triticum aestivum L. cv. "Wiwa") plots $(5 \times 20 \mathrm{~m})$ of two farming systems, resulting in 24 subplots. As the aim of the current study was to evaluate the general performance of the rainout-shelter, we did not differentiate between the two farming systems but treated the plots of the two systems as independent replicates ( $n=8$ plots).

The three treatments were (i) a precipitation reduction treatment with rainout-shelters (R) (ii) a rainout-shelter control treatment with a modified rainout-shelter that allowed for ambient precipitation levels to assess rainout-shelter artifacts
(RC) and (iii) an untreated ambient control without any rainout-shelter (C). Treatments were established in a row, both at the near and the far end of each plot. In order to prevent mutual interference of rainout-shelter and rainoutshelter control treatments, these were never located side by side (Supplementary Figure 1). Instead, rainout-shelter and rainout-shelter control treatments were always located next to the ambient control treatment or had no adjacent treatment. Positions of treatments were randomized across the eight plots within these limitations, whereas every treatment combination occurred twice across the DOK trial. We maintained a distance between treatments as well as between treatments and field edges of at least $0.5 \mathrm{~m}$. To avoid potential confounding edge effects such as lateral inflow of precipitation on our measurements, we determined all abiotic conditions only in the center of each plot $(1.5 \times 1 \mathrm{~m})$. Approximately 2 month after rainout-shelter establishment, we quantified this edge effect by measuring gradients in soil humidity (see section Data Collection for details).

\section{Rainout-Shelter Design}

The rainout-shelters consist of a tubular steel frame $(2.5 \times 2.5 \times$ 1.2-1.7 m, $6.25 \mathrm{~m}^{2}$; Figure 1A) supporting 12 V-shaped clear and

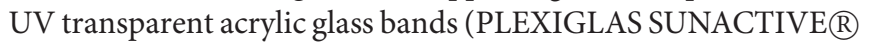
GS 2458, Evonik Perfomances Materials GmbH, Darmstadt, Germany). Each band had a length of $2,500 \mathrm{~mm}$, an inner flange leg length of $96 \mathrm{~mm}$, an angle of $90^{\circ}$ and a thickness of $3 \mathrm{~mm}$. According to Equation 1, 12 acrylic bands should exclude $65 \%$ of the ambient precipitation. The amount of intercepted precipitation can easily be adjusted by changing the number of 
bands (see also Yahdjian and Sala, 2002).

$$
\text { Intercepted precipitation [\%] }=\frac{N * \text { Width of band }}{\text { Shelter width }} * 100 \% \text { (1) }
$$

Equation (1): Amount of precipitation intercepted (\%) by number of bands $(N)$. For the current design: $N=$ number of bands (here 12), width of the bands: $135.8 \mathrm{~mm}$, shelter width: $2,500 \mathrm{~mm}$.

In order to alter natural light conditions as little as possible, we chose a roof band material that is as permeable for the full range of PAR and transparent for most wavelengths of UV-a and -b radiation (Transmission: $380-780 \mathrm{~nm} \geq 90 \%, 315 \mathrm{~nm} \geq 80 \%$ ), but is still resistant against weathering and possible damage under field conditions [for details see http://www.plexiglas. de/sites/lists/PM/DocumentsAP/222-6-PLEXIGLAS-GS-UVdurchlaessig-de.pdf (in German)]. The acrylic bands were fixed to the steel frame by custom-made holders (Figure 1B) on the front steel pipe and an additional central parallel steel pipe (Figure 1C). The rainout-shelters have a maximum height of $1.7 \mathrm{~m}$ and a minimum height of $1.2 \mathrm{~m}$, resulting in an incline of $13^{\circ}$, which guarantees water run-off, but the incline can be adjusted if required. The horizontal roof parts rest on four supporting steel pipes anchored in the soil using commercially available metal drive-in sleeves (Figure 1A). This construction allows to temporarily remove the rainout-shelter during management actions without much effort. Shelters were located with the lower side facing west, as this is the prevailing wind direction at the study site. Water that was collected by the acrylic bands was channeled via rain gutters (Figures 1D,E) at the lower side of the steel frame into $310 \mathrm{~L}$ rain barrels (Figure 1F). This prevented a reflux of water onto the experimental plot under the roof and allowed to measure the amount of intercepted precipitation.

As mentioned above, we established a rainout-shelter control treatment that was identical to the rainout-shelter except that the $12 \mathrm{~V}$-shaped acrylic glass bands were turned over allowing the precipitation to fall onto the plot under the rainout-shelter control. This treatment made it possible to quantify potential artifacts. More details on the parts and the assembly of the rainout-shelters are given in Supplementary Tables 1, 2. A blankfree cutting plan for the pipes, the distances between band holders and details on the adaptor plates for the rain-gutter brackets, the holders for the acrylic glass bands and the clamping claws are shown in Supplementary Figures 7-12. One rainout-shelter as we present it in this study costs $730 €(630 €$ for a control shelter).

\section{Data Collection}

To assess the actual percentage of precipitation intercepted by the rainout-shelters, we used the precipitation data from a close-by weather station in Therwil, Switzerland (http://www.bodenmessnetz.ch/messwerte/datenabfrage)

as well as data from the on-field meteorological station (Campbell-CR1000) and regularly measured the amount of intercepted precipitation in the rain barrels. We then subtracted the average amount of precipitation collected in the rain barrels from the amount of rain that fell on the ambient control plot $\left(6.25 \mathrm{~m}^{2}\right)$ to calculate the actual percentage of precipitation that was intercepted by the rainout-shelters.

From April to June 2017 we took weekly measurements at three randomly chosen locations within the center of all 24 subplots to assess volumetric soil water content in $0-6 \mathrm{~cm}$ depth (in approx. $75 \mathrm{~cm}^{3}$ soil) using a handheld Time Domain Reflectometry (TDR)-device (ML-2x ThetaProbe, Delta-T). Each month, we sampled soil in the center of all experimental plots $(0-20 \mathrm{~cm}$ depth), oven-dried the soil sample to constant weight, and calculated the soil water content (\% water, based on $\mathrm{g} \mathrm{H}_{2} \mathrm{O} / \mathrm{g}$ dry weight). In May 2017, we assessed the extent of lateral water movement ("edge effect") under the rainout-shelter and the rainout-shelter control in a subset of 2 plots, each along transects from north to south and from west to east (see also Yahdjian and Sala, 2002). Along each transect, we measured the volumetric water content using the TDR device in $0-6 \mathrm{~cm}$ depth in triplicates at 13 measurement positions $(25 \mathrm{~cm}$ apart from each other, see Supplementary Figure 2). For each transect, rainout-shelter type and plot, we performed a one-way ANOVA to assess the effect of the measurement position (distance from shelter edge) on the soil water content, followed by a Tukey's honestly significance post-hoc test. We confirmed the fit of the models by visual inspection of the residual plots, which did not reveal any obvious deviations from homoscedasticity or normality.

We assessed possible shelter effects on the microclimate using iButtons temperature loggers (DS1922L/T/E/S; accuracy: $0.0625^{\circ} \mathrm{C}, 1 \mathrm{record} / \mathrm{h}$ ) by constantly measuring air temperature at a height of $0.1 \mathrm{~m}$ in the center of the respective subplots (total $N=3$ subplots, each one iButton in a rainout-shelter treatment, a rainout-shelter control treatment and an ambient control treatment), and $1.2 \mathrm{~m}$ (total $N=6$ subplots, each one iButton per treatment in 2 plots) as well as on soil temperature at $0.1 \mathrm{~m}$ depth (total $N=6$ subplots, each one iButton per treatment, 2 plots). For each of the three temperature datasets, we calculated a daily mean temperature to determine the day with the highest and lowest temperature, respectively. We then averaged the individual hourly temperature readings of the highest temperature day, the respective previous and following day for each of the three treatments to calculate mean differences and standard deviations between rainoutshelter treatments and ambient control plots. We used this information to describe potential shelter artifacts under the two most extreme environmental scenarios. In the same way, we also proceeded with the lowest temperature day. In cases the lowest/highest day was the first/last day of the recording period, we used the two following or preceding days, respectively.

We harvested aboveground biomass of the wheat plants 4,8 , and 13 weeks after rainout-shelter establishment from subplots $(20 \times 50 \mathrm{~cm}, 2$ wheat rows), each subplot located in the core area of the experimental plots.

The analysis of all data and drawing of all figures (excluding the CAD drawings) were done using $\mathrm{R}$ ( $\mathrm{R}$ Core Team, 2016) and the package ggplot2 (Wickham, 2009). CAD drawings were created with Siemens NX. 


\section{RESULTS}

\section{Precipitation Interception, Soil Moisture, and Edge Effect}

In total, precipitation under the rainout-shelters was $70.6 \mathrm{~mm}$ (19th of April to 06th of June 2017) corresponding to a precipitation reduction of $64.9 \%$ as compared to the ambient precipitation $(201.1 \mathrm{~mm})$ at the study site. This observed value is almost identical to the expected precipitation exclusion values based on a priori calculations for a shelter with 12 bands (-65.2\%, Equation 1). In the week prior to rainout-shelter establishment (baseline assessment; T0), all treatment plots had comparable soil water contents [ambient control (C): $29.37 \pm$ $1.07 \%$ (Mean $\pm \mathrm{SD}$ ), rainout-shelter control (RC): $28.87 \pm 1.21 \%$, rainout-shelter (R): $29.10 \pm 1.27 \%$; Figure 2A]. There was little precipitation between T0 and the first assessment $(\mathrm{T} 1 ; 21.2 \mathrm{~mm}$ in 36 days, Figure 2C). Soil water content under both shelter types therefore differed only slightly from the ambient control plots [R: -4.0 percentage points $(\mathrm{pp}) \pm 1.54 \mathrm{pp}, n=8$, RC: $-1.98 \mathrm{pp} \pm 1.50 \mathrm{pp}, n=8$ ] at T1 (35 days after rainoutshelter establishment). The amount of precipitation increased between $\mathrm{T} 1$ and the second assessment (T2; $121.6 \mathrm{~mm}$ in 27 days; Figure 2C) and we recorded more pronounced differences in the soil water content between the rainout-shelter treatment plots and the ambient control plots (R: $-11.06 \mathrm{pp} \pm 0.71 \mathrm{pp}, n$ $=8$ ). In contrast, the soil water content in the rainout-shelter control treatment plots was only weakly lower as compared to the ambient control plot (RC: $-2.66 \mathrm{pp} \pm 1.27 \mathrm{pp}, n=8$ ). Between $\mathrm{T} 2$ and the third assessment (T3), precipitation was low again (75.6 $\mathrm{mm}$ in 35 days; Figure 2C), and differences between the two rainout-shelters and ambient control decreased (R: $-4.68 \mathrm{pp} \pm$ $1.65 \mathrm{pp}, \mathrm{RC}:-2.24 \mathrm{pp} \pm 1.39 \mathrm{pp})$.

Data from weekly soil moisture measurements as determined with the TDR device in the top $6 \mathrm{~cm}$ of soil also revealed only minor deviations in soil water content between the rainout-shelter control treatment and the ambient control. The data further confirmed that soil moisture content in the rainout-shelter treatment was considerably lower already 1 month after rainout-shelter establishment as compared to the ambient control treatment (Figure 2B). Edge effects on soil moisture were only detectable up to $75 \mathrm{~cm}$ under shelter the area (Figures 3A,B, Supplementary Figures $3 \mathrm{~A}, \mathrm{~B})$.

\section{Shelter Effect on Microclimate}

Our rainout-shelters had slight impacts on air temperature at $1.2 \mathrm{~m}$ height (06th of April to 20th of June 2017; Supplementary Figure 4) in comparison to ambient control plots (R: $-0.55 \pm$ $2.76^{\circ} \mathrm{C}, n=3648$; RC: $\left.-0.59 \pm 2.58^{\circ} \mathrm{C}, n=3648\right)$. During the period with high ambient temperatures (18th to 20th of June 2017), we recorded reduced temperatures up to $1.0^{\circ} \mathrm{C}$ in the two rainout-shelter treatments as compared to the ambient control plot (rainout-shelter; R: $-0.92 \pm 3.46^{\circ} \mathrm{C}, n=144$; rainoutshelter control; RC: $-0.94 \pm 3.3^{\circ} \mathrm{C}, n=144$; Figure 4A). During the period with rather low temperatures (26th to 28th of April 2017) air temperature was only marginally lower under both rainout-shelter types $\left(\mathrm{R}:-0.11 \pm 1.27^{\circ} \mathrm{C}, n=144\right.$; $\mathrm{RC}:-0.23$

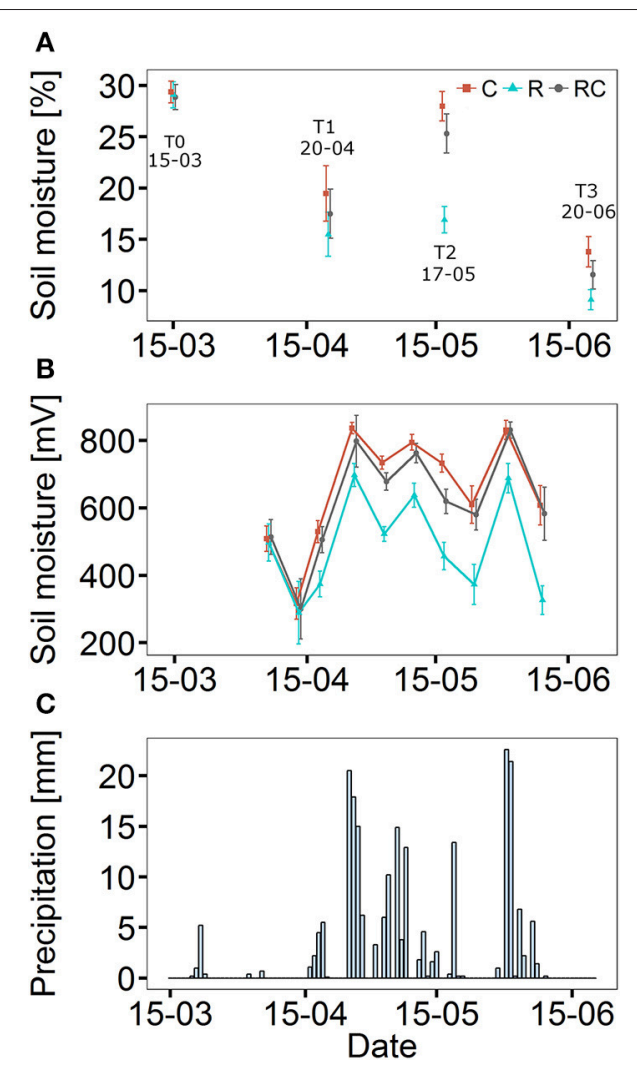

FIGURE 2 | (A) Rainout-shelter effect on soil water content (\% water, based on $\mathrm{g} \mathrm{H}_{2} \mathrm{O} / \mathrm{g}$ soil dry weight) as assessed in the top $20 \mathrm{~cm}$ (means \pm standard deviation, $n=8$ ) on March 15, 2017 (baseline assessment; T0), April 20, 2017 (first assessment; T1), May 17, 2017 (second assessment; T2), and June 20, 2017 (third assessment; T3); (B) rainout-shelter effects on volumetric soil water content measured with a TDR device (ML-2x ThetaProbe, Delta-T) in $0-6 \mathrm{~cm}$ depth. Data points represent means \pm standard deviation, $n=8$; (C) Precipitation ( $\mathrm{mm}$ in $24 \mathrm{~h}$ ) during the rainfall manipulation experiment. Data between April 5 to May 8, 2017 derived from the online database http://www. bodenmessnetz.ch (station in Therwil), all other data was recorded by the on-site weather station (Campbell-CR1000).

$\left.\pm 1.28^{\circ} \mathrm{C}, n=144\right)$ as compared to the ambient control plots (Figure 4B).

The rainout-shelters had very little impact on air temperature at $10 \mathrm{~cm}$ above soil surface (07th of April to 05th of June 2017; Supplementary Figure 5) as compared to ambient control plots (R: $\left.+0.19 \pm 1.25^{\circ} \mathrm{C}, n=1,440 ; \mathrm{RC}:+0.19 \pm 1.06^{\circ} \mathrm{C}, n=1,440\right)$. Deviations from ambient temperature readings were low during the high $\left(\mathrm{R}:+0.11 \pm 1.06^{\circ} \mathrm{C}, n=72\right.$; $\mathrm{RC}:+0.19 \pm 0.88^{\circ} \mathrm{C}, n=$ 72; Figure 5A) and low (R: $+0.17 \pm 1.56^{\circ} \mathrm{C}, n=72$; $\mathrm{RC}:-0.15$ $\pm 1.36^{\circ} \mathrm{C}, n=72$; Figure $5 \mathrm{~B}$ ) temperature period.

Similarly, the two rainout-shelter types had little impact on soil temperature (07th of April to 05th of June 2017; Supplementary Figure 6) in comparison to ambient control plots $\left(\mathrm{R}:+0.64 \pm 0.53^{\circ} \mathrm{C}, n=6,076\right.$; $\left.\mathrm{RC}:+0.39 \pm 0.33^{\circ} \mathrm{C}, n=6,076\right)$. Deviations from ambient temperature readings were low during the high $\left(\mathrm{R}:+1.02 \pm 0.46^{\circ} \mathrm{C}, n=828\right.$; $\mathrm{RC}:+0.63 \pm 0.31^{\circ} \mathrm{C}, n=$ 828; Figure 6A) and low (R: $+0.14 \pm 0.52^{\circ} \mathrm{C}, n=828$; RC: +0.20 $\pm 0.41^{\circ} \mathrm{C}, n=828$; Figure $6 \mathrm{~B}$ ) temperature phase. 


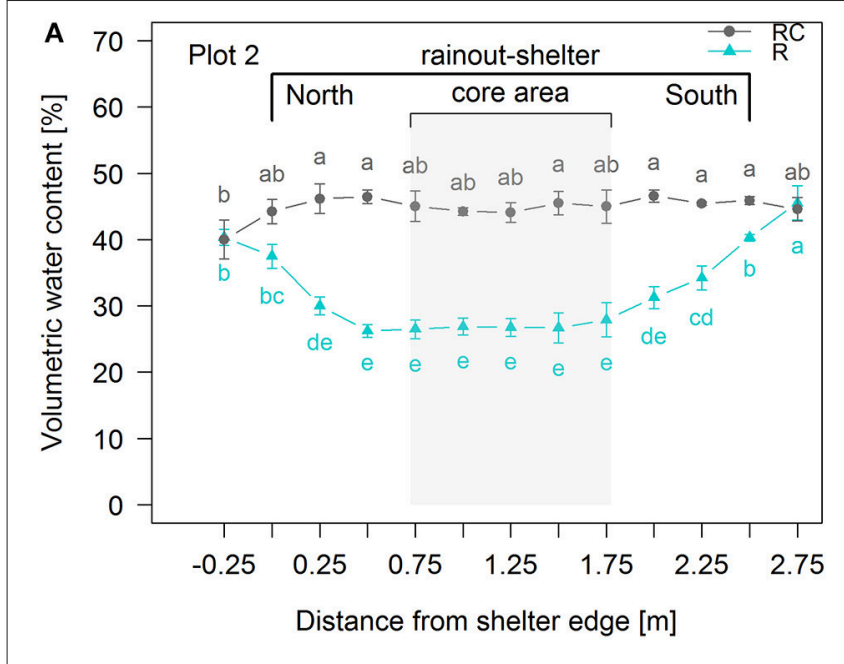

B

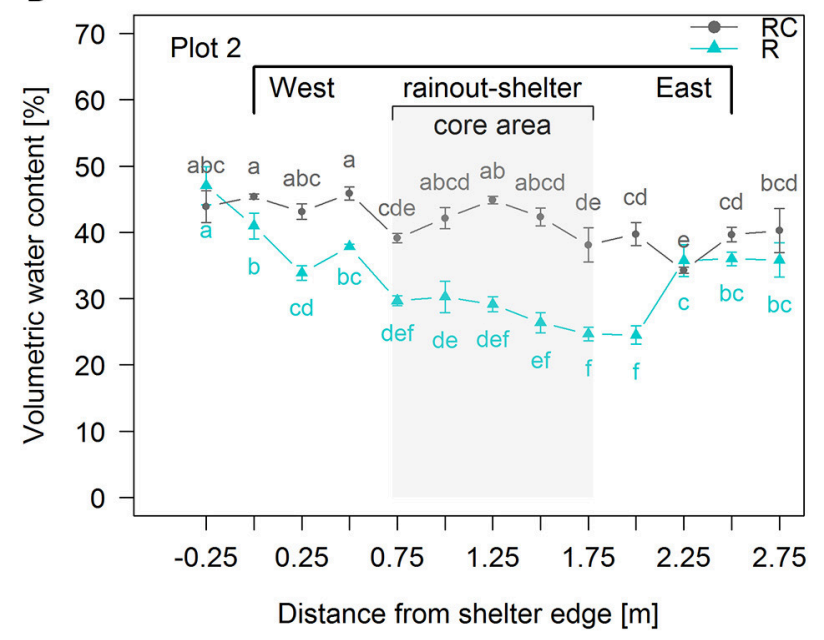

FIGURE 3 | (A) Assessment of the soil water content under the rainout-shelter $(R)$ and the rainout-shelter control $(R C)$ using a handheld TDR device (ML-2x ThetaProbe, Delta-T) in the top $6 \mathrm{~cm}$ of soil. Data points represent means \pm standard deviation, $n=3$. We measured along transects located (A)

North-South and (B) West-East in two of the eight experimental plots (Plot 2, see also Supplementary Figure 3) on May 15, 2017. Data was analyzed by a one-way ANOVA followed by a Tukey's honestly significance post-hoc test. Means within treatments not sharing the same letter are significantly different (Tukey HSD, $P<0.05$ ). Rainout-shelters were located with the lower side facing west as this is the prevailing wind direction at the study site.

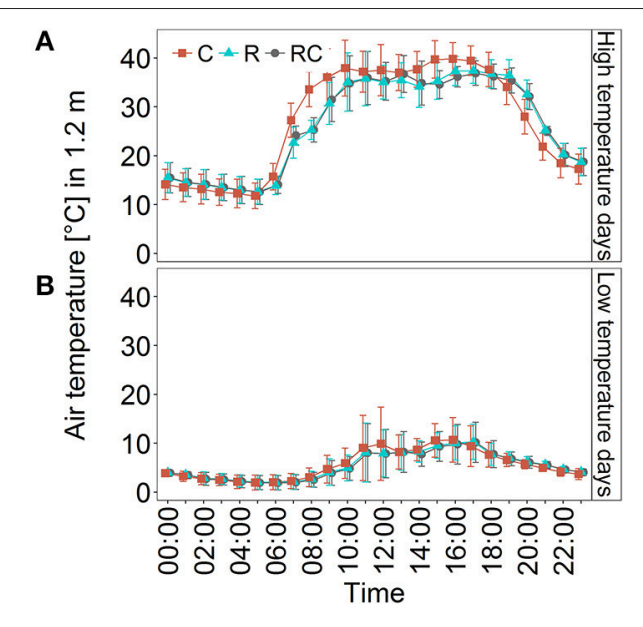

FIGURE 4 | Air temperature $\left({ }^{\circ} \mathrm{C}\right)$ as measured in $1.2 \mathrm{~m}$ height using iButton temperature loggers under the rainout-shelter $(R)$, the rainout-shelter control treatment $(\mathrm{RC})$, and the ambient control plots $(\mathrm{C})$. Data points represent hourly temperature measurements (means \pm standard deviation) of two plots and 3 days during (A) a high temperature phase (June 18-20, 2017) and (B) a low temperature phase (April 26-28, 2017).

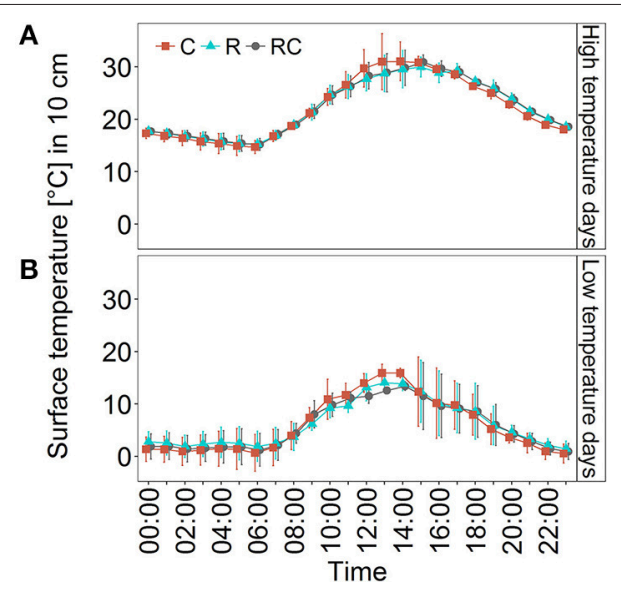

FIGURE 5 | Surface temperature $\left({ }^{\circ} \mathrm{C}\right)$ as measured in $0.1 \mathrm{~m}$ height using iButton temperature loggers under the rainout-shelter $(R)$, the rainout-shelter control treatment $(\mathrm{RC})$, and the ambient control plots $(\mathrm{C})$. Data points represent hourly temperature measurements (means \pm standard deviation) of one plots and 3 days during (A) a high temperature phase (May 28-30, 2017) and (B) a low temperature phase (April 18-20, 2017).

artifacts on microclimatic conditions under the shelter, allow for replication across larger spatial scales and be stable enough to persist under field conditions. The rainout-shelter design described here fulfils all these requirements.

\section{Roof Performance}

The rainout-shelters effectively excluded $64.9 \%$ of the ambient precipitation, very close to the a priori calculated rain exclusion of $65.2 \%$. A precise prediction of the amount of excluded water depending on the number of acrylic bands in the shelter 


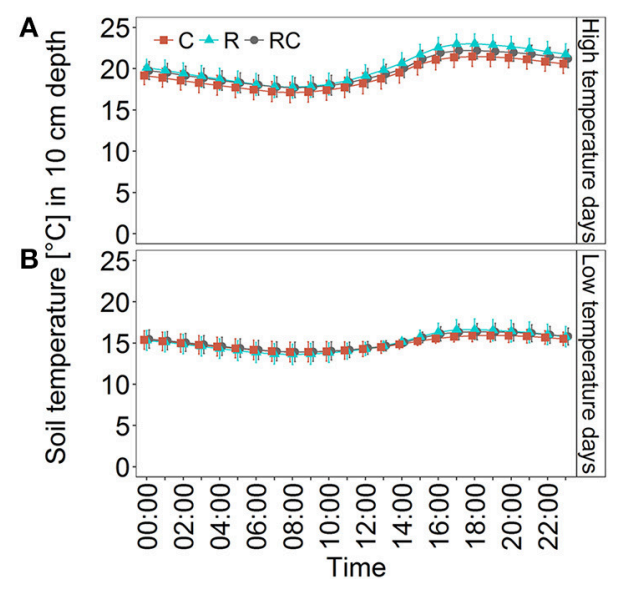

FIGURE 6 | Soil temperature $\left({ }^{\circ} \mathrm{C}\right)$ as measured in $10 \mathrm{~cm}$ depth using iButton temperature loggers under the rainout-shelter $(R)$, the rainout-shelter control treatment $(\mathrm{RC})$, and the ambient control plots $(\mathrm{C})$. Data points represent hourly temperature measurements (means \pm standard deviation) of two plots and 3 days during (A) a high temperature phase (June 18-20, 2017) and (B) a low temperature phase (June 6-8, 2017).

construction is thereby possible and provides a crucial tool for the planning of field experiments.

In addition to measurements of rain drainage and natural precipitation levels, soil water content is an important parameter for the evaluation of the performance of rainout-shelters. Soil water content was very similar in the rainout-shelter control and the ambient control treatment during the whole sampling campaign, and lowest in the rainout-shelter treatment for most of the study period. After an initial phase with similar soil water content in each of the three treatments, soil water content was constantly lower under the rainout-shelter as compared to the ambient control and the rainout-shelter control plots. The soil water content in the experimental treatments started to differ after the first heavy rain events supporting results of previous studies (Mikkelsen et al., 2008; Vogel et al., 2013). Although the early summer 2017 was characterized by several short drought-like periods, the developed rainout-shelters still resulted in differences in soil water content, making the design also suitable for regions with drier climatic conditions.

The spatial extent of an edge effect defines the size of the suitable sampling area under a rainout-shelter. However, only few studies determined edge effects by measurements in the field (Yahdjian and Sala, 2002; Beier et al., 2004). In this study, the maximum edge effect was $0.75 \mathrm{~m}$ beyond the edges of the $2.5 \times 2.5 \mathrm{~m}$ roof area, resulting in a $1.00 \times 1.00 \mathrm{~m}$ core area receiving full treatment effect and thereby being available for measurements. The assessment of edge effects was conducted after a period of rain events, so that the edge effect of $0.75 \mathrm{~m}$ can be considered as the maximum edge effect. The chosen dimensions of the rainout-shelters $(2.5 \times 2.5 \times 1.2-1.7 \mathrm{~m})$, which mainly determine the size of the edge effect, result in a reasonable balance between available sampling area, handling and material costs.
The performance of the rainout-shelter material in terms of stability and practicability was excellent. The construction was not damaged by heavy hail storms or rain events as well as temperatures below 0 and above $30^{\circ} \mathrm{C}$, and the UV transparent bands did not show any signs of weathering over the study period. The plastic rain gutters slightly deformed during hot summer days and should be replaced by metal rain gutters, especially at field sites with higher maximum temperatures. The specific requirements of field studies in agricultural areas, i.e., the need to remove the shelters for management activities, were successfully met by our removable rainout-shelter construction (note that at least four people are needed to move the rainout-shelter). The workload for maintenance was limited to the drainage of the water barrels which took place every 1 to 2 weeks, depending on precipitation events. This limited workload for maintenance allows managing several replicated rainout-shelters even if in use for longer periods of time.

\section{Microclimate}

Rainout-shelters may cause lower air temperature due to the interception of radiation (Yahdjian and Sala, 2002), on the one hand, on the other hand a greenhouse effect, enhanced by reduced air flow under shelters, may cause higher temperature (Svejcar et al., 1999; Vogel et al., 2013). Both artifacts may bias the results of rainout-shelter experiments.

In this study, air temperature at 1.2 and $0.1 \mathrm{~m}$ height above ground was little affected by the rainout-shelter, especially during periods of low ambient temperature. This suggests that the spacing of the acrylic bands allowed sufficient airflow to prevent greenhouse effects under the rainout-shelters. A setup with more acrylic bands and subsequently a narrower spacing between bands, however, may have stronger impact on the temperature regimes. The facilitation of air movement is especially crucial in systems with high and dense plant growth such as cereal crops. In the current study, winter wheat plants in their final growth stages almost reached the height of the rainout-shelter, but temperature measurements still did not indicate greenhouse effects (Figure 4A). However, differences in air temperatures of up to $1^{\circ} \mathrm{C}$ during periods of high ambient temperature confirm the need of a rainout-shelter control treatment. Our data showed virtually identical temperature under the two rainoutshelter types (Figures 4, 5, Supplementary Figures 4, 5), thereby supporting the suitability of a rainout-shelter control, especially under constantly warm conditions.

Soil temperature was slightly higher under the rainout-shelter as compared to the ambient control, but only during periods of high ambient temperature and differences to the control plot were more pronounced under the rainout-shelter than under the rainout-shelter control (Figure 6). This might be caused by lower soil moisture under the rainout-shelter and consequently lower total water content that buffer heating of the soil by solar radiation. Accordingly, the soil temperature was highest in the rainout-shelter treatment in which soil moisture contents were lowest and only slightly increased in the rainout-shelter control treatment which had intermediate soil moisture contents. This artifact cannot be avoided, because lower soil moisture is the goal of the rainout-shelter. 
The interception of radiation was minimized by the use of highly UV-permeable acrylic glass bands as roof material (transmission at $315 \mathrm{~nm} \geq 80$, transmission $380-780 \mathrm{~nm} \geq 90 \%$ ). The use of this material guaranteed natural PAR levels under the rainout shelters.

\section{Plant Performance}

The production of above-ground biomass was not significantly affected by the exclusion of rain, neither 4,8 , or 13 weeks after rainout-shelter establishment. We suspect that the exclusion level we selected was not sufficient to dry out the soil within the relatively short duration of our experiment. In order to reduce soil moisture also at lower depths, it seems necessary to extend the duration of the experiment and/or increase the amount of excluded rainfall. It is notable that in annual crop fields longer exclusion periods are almost not possible during the growing season (tillering to harvest is only a few months) and that a more complete exclusion of rainfall over such periods is unrealistic according to all climate change scenarios.

\section{CONCLUSION}

The rainout-shelter design presented here is well-suited for experimental manipulations of precipitation in open land ecosystems and agricultural fields in particular. Microclimatic conditions under the rainout-shelter were largely unaffected and the intended alteration of precipitation levels followed our a-priori calculations. Slightly lower under-shelter air temperatures during high ambient temperature phases were the only unintended artifacts we measured. These artifacts were reflected by the rainout-shelter control treatment allowing to account for them. Soil moisture differences between the different treatments established after the first rain events and remained present throughout the experiment. Animated 3-D drawings of the rainout-shelter design (note that the PDF reader needs to be able to show animated PDFs), detailed descriptions of shelter construction, manuals for their setup and a list of material allow future users to apply the developed design in their studies. With this study, the authors hope to promote the use of rainout-shelters to simulate and investigate climate change effects on agricultural systems, which is crucial given the risk of crop yield losses under altered future precipitation regimes.

\section{REFERENCES}

Beier, C., Beierkuhnlein, C., Wohlgemuth, T., Penuelas, J., Emmett, B., Körner, C., et al. (2012). Precipitation manipulation experiments challenges and recommendations for the future. Ecol. Lett. 15, 899-911. doi: 10.1111/j.1461-0248.2012.01793.x

Beier, C., Emmett, B., Gundersen, P., Tietema, A., Estiarte, M., Gordon, C., et al. (2004). Novel approaches to study climate change effects on terrestrial ecosystems in the field: drought and passive nighttime warming. Ecosystems 7 , 583-597. doi: 10.1007/s10021-004-0178-8

Blankinship, J. C., Niklaus, P. A., and Hungate, B. A. (2011). A metaanalysis of responses of soil biota to global change. Oecologia 165, 553-565. doi: 10.1007/s00442-011-1909-0

\section{AUTHOR CONTRIBUTIONS}

DK has been involved in the conception of the rainout-shelters and their set-up, was in charge of the field study, has collected and analyzed the data and has written the manuscript. SM has been involved in the rainout-shelter set-up, has collected and analyzed the data and has written the manuscript. HB has designed and constructed all major parts of the rainoutshelters, was in charge of the setup manual, the final decision of materials and suppliers and the CAD drawings. AF has been involved in the conception of the rainout-shelters and the study design, and has commented on the manuscript. PM contributed to the conception of the rainout-shelters, was involved in the development and conductance of the field study in the DOK trial and commented on the manuscript. SS has contributed to the rainout-shelter design and commented on the manuscript. MvK has contributed to the sampling design and statistical analyses, provided the iButtons and commented on the manuscript. KB has developed the idea for rainout-shelter experiments in the framework of this project, has reviewed the existing literature on rainout-shelter experiments and has contributed to design decisions and identification of suitable materials and suppliers. He has contributed to the manuscript.

\section{ACKNOWLEDGMENTS}

We thank S. Grau, M. Sauter, F. Perrochet, and J. Meier for their help with field work and M. Tichy at Bröking-Plastic $\mathrm{GmbH} \&$ Co. KG for the detailed advice on acrylic glass options. We further acknowledge support by the Open Access Publication Funds of the Göttingen University. We also thank the two referees for their constructive input. This research was funded through the 2015-2016 BiodivERsA COFUND call for research proposals, with the national funders Estonian Research Council (ETAG), German Research Foundation (DFG), Ministry of Economy and Competitiveness (MINECO), The Swedish Research Council (Formas), and Swiss National Science Foundation (SNSF).

\section{SUPPLEMENTARY MATERIAL}

The Supplementary Material for this article can be found online at: https://www.frontiersin.org/articles/10.3389/fenvs. 2018.00014/full\#supplementary-material

Canarini, A., Carrillo, Y., Mariotte, P., Ingram, L., and Dijkstra, F. A. (2016). Soil microbial community resistance to drought and links to C stabilization in an Australian grassland. Soil Biol. Biochem. 103, 171-180. doi: 10.1016/j.soilbio.2016.08.024

Castro, H. F., Classen, A. T., Austin, E. E., Norby, R. J., and Schadt, C. W. (2010). Soil microbial community responses to multiple experimental climate change drivers. Appl. Environ. Microbiol. 76, 999-1007. doi: 10.1128/AEM.02874-09

CH2011 (2011). Swiss Climate Change Scenarios CH2011. Zurich: C2SM, MeteoSwiss, ETH, NCCR Climate and OcCC.

EEA (2017). Climate Change, Impacts and Vulnerability in Europe 2016. Luxembourg: Publications Office of the European Union.

Falloon, P., and Betts, R. (2010). Climate impacts on european agriculture and water management in the context of adaptation and mitigation - the 
importance of an integrated approach. Sci. Total Environ. 408, 5667-5687. doi: 10.1016/j.scitotenv.2009.05.002

Fay, P. A., Carlisle, J. D., Knapp, A. K., Blair, J. M., and Collins, S. L. (2000). Altering rainfall timing and quantity in a mesic grassland ecosystem: design and performance of rainfall manipulation shelters. Ecosystems 3, 308-319. doi: 10.1007/s100210000028

Fay, P. A., Carlisle, J. D., Knapp, A. K., Blair, J. M., and Collins, S. L. (2003). Productivity responses to altered rainfall patterns in a C4-dominated grassland. Ecosyst. Ecol. 137, 245-251. doi: 10.1007/s00442-003-1331-3

Fliessbach, A., Oberholzer, H. R., Gunst, L., and Mäder, P. (2007). Soil organic matter and biological soil quality indicators after 21 years of organic and conventional farming. Agric. Ecosyst. Environ. 118, 273-284. doi: 10.1016/j.agee.2006.05.022

Gimbel, K. F., Felsmann, K., Baudis, M., Puhlmann, H., Gessler, A., Bruelheide, H., et al. (2015). Drought in forest understory ecosystems a novel rainfall reduction experiment. Biogeosciences 12, 961-975. doi: 10.5194/bg-12-961-2015

IPCC (2014). Climate Change 2014: Synthesis Report. Contribution of Working Groups I, II and III to the Fifth Assessment Report of theIntergovernmental Panel on Climate Change. Geneva: IPCC.

Mäder, P., Fliessbach, A., Dubois, D., Gunst, L., Fried, P., and Niggli, U. (2002). Soil fertility and biodiversity in organic farming. Science 296, 1694-1697. doi: $10.1126 /$ science. 1071148

Mikkelsen, T. N., Beier, C., Jonasson, S., Holmstrup, M., Schmidt, I. K., Pilegaard, K., et al. (2008). Experimental design of multifactor climate change experiments with elevated $\mathrm{CO}_{2}$, warming and drought: the CLIMAITE project. Funct. Ecol. 22, 185-195. doi: 10.1111/j.1365-2435.2007.01362.x

Olesen, J. E., and Bindi, M. (2002). consequences of climate change for european agricultural productivity, land use and policy. Eur. J. Agron. 16, 239-262. doi: 10.1016/S1161-0301(02)00004-7

Parra, A., Ramírez, D. A., Resco, V., Velasco, Á., and Moreno, J. M. (2012). Modifying rainfall patterns in a mediterranean shrubland: system design, plant responses and experimental burning. Int. J. Biometeorol. 56, 1033-1043. doi: 10.1007/s00484-011-0517-3

Poll, C., Marhan, S., Back, F., Niklaus, P. A., and Kandeler, E. (2013). Fieldscale manipulation of soil temperature and precipitation change soil $\mathrm{CO}_{2}$ flux in a temperate agricultural ecosystem. Agric. Ecosyst. Environ. 165, 88-97. doi: 10.1016/j.agee.2012.12.012

Porporato, A., Daly, E., and Rodriguez-Iturbe, I. (2004). Soil water balance and ecosystem response to climate change. Am. Nat. 164, 625-632. doi: $10.2307 / 3473173$

Prechsl, U. E., Burri, S., Gilgen, A. K., Kahmen, A., and Buchmann, N. (2015). No shift to a deeper water uptake depth in response to summer drought of two lowland and sub-alpine $C_{3}$-grasslands in Switzerland. Oecologia 177, 97-111. doi: 10.1007/s00442-014-3092-6

R Core Team (2016). R: A Language and Environment for Statistical Computing. Vienna. Available online at: https://www.r-project.org/

Russo, S., Dosio, A., Sterl, A., Barbosa, P., and Vogt, J. (2013). Projection of occurrence of extreme dry-wet years and seasons in Europe with stationary and nonstationary standardized precipitation indices. J. Geophys. Res. Atmos. 118, 7628-7639. doi: 10.1002/jgrd.50571

Spinoni, J., Naumann, G., and Vogt, J. (2015). Spatial patterns of European droughts under a moderate emission scenario. Adv. Sci. Res. 12, 179-186. doi: 10.5194/asr-12-179-2015

Svejcar, T., Angell, R., and Miller, R. (1999). Fixed location rain shelters for studying precipitation effects on rangelands. J. Arid Environ. 42, 187-193.

Trnka, M., Oelsen, J. E., Kersebaum, K. C., Skjelvag, A. O., Eitzinger, J., Seguin, B., et al. (2011). Agroclimatic conditions in europe under climate change. Glob. Chang. Biol. 17, 2298-2318. doi: 10.1111/j.1365-2486.2011.0 2396.x

Vogel, A., Fester, T., Eisenhauer, N., Scherer-Lorenzen, M., Schmid, B., Weisser, W. W., et al. (2013). Separating drought effects from roof artifacts on ecosystem processes in a grassland drought experiment. PLoS ONE 8:e70997. doi: 10.1371/journal.pone.0070997

Wickham, H. (2009). ggplot2: Elegant Graphics for Data Analysis. New York, NY: Springer-Verlag.

Wu, Z., Dijkstra, P., Koch, G. W., Penuelas, J., and Hungate, B. A. (2011). Responses of terrestrial ecosystems to temperature and precipitation change: a meta-analysis of experimental manipulation. Glob. Chang. Biol. 17, 927-942. doi: 10.1111/j.1365-2486.2010.02302.x

Yahdjian, L., and Sala, O. E. (2002). A rainout shelter design for intercepting different amounts of rainfall. Oecologia 133, 95-101. doi: $10.1007 /$ s00442-002-1024-3

Conflict of Interest Statement: The authors declare that the research was conducted in the absence of any commercial or financial relationships that could be construed as a potential conflict of interest.

Copyright (C) 2018 Kundel, Meyer, Birkhofer, Fliessbach, Mäder, Scheu, van Kleunen and Birkhofer. This is an open-access article distributed under the terms of the Creative Commons Attribution License (CC BY). The use, distribution or reproduction in other forums is permitted, provided the original author(s) and the copyright owner are credited and that the original publication in this journal is cited, in accordance with accepted academic practice. No use, distribution or reproduction is permitted which does not comply with these terms. 